\title{
Educação Física e esportes na Ação Integralista Brasileira: Hollanda Loyola e a educação do corpo ${ }^{1}$
}

CDD. 20.ed. 616.89

796.017

\author{
Renata Duarte SIMÕES* \\ Silvana Vilodre GOELLNER ${ }^{* *}$
}

*Faculdade de Educação, Universidade de São Paulo. **Escola Superior de Educacão Física, Universidade Federal do Rio Grande do Sul.

\section{Resumo}

Investiga como a Ação Integralista Brasileira, movimento social que emerge no Brasil Republicano, educava corporalmente, por meio da Educação Física e dos esportes, membros inscritos em suas fileiras. Analisa artigos publicados em A Offensiva, jornal doutrinário e prescritivo do movimento, publicados de 17/05/1934 a 19/03/1938, com destaque para os artigos de Francisco de Assis Hollanda Loyola. Os escritos de Loyola, Mestre de Campo da Milícia e diretor da Escola de Instructores de Educação Physica integralista, ganham destaque porque instituíram um modo inovador de conceber a prática esportiva e o treinamento físico na AIB. Loyola conquistou espaço no jornal e traçou o "Plano Geral" de Educação Física voltado para as necessidades e características do povo brasileiro, aspecto enfatizado pelo autor. Concluiu que agregando as prescrições de Loyola a práticas ritualistas e simbólicas, o integralismo impunha ao corpo um modo muito próprio de ser integralista, modo de ser um "soldado-integral".

UnIteRMos: Educação física; Ação Integralista Brasileira; Hollanda Loyola.

\section{Introdução}

$\mathrm{Na}$ década de 30 , sobre o corpo foi dirigida a atenção de médicos, educadores, engenheiros, professores e instituições como o exército, a Igreja e a escola. A compreensão que perpassava os discursos desses profissionais e os espaços em que atuavam era de que o corpo precisava ser educado física e moralmente, pois, convenientemente educado, favoreceria o desenvolvimento do espírito, operando também como um instrumento útil a serviço dos interesses da Nação. O corpo fisicamente educado facultaria o desenvolvimento "das mais elevadas faculdades morais" (SALZANo citado por LenHaro, 1986, p.75-7).

Nesse contexto, imprimia-se um sentido de consciência social ao aprimoramento físico. A nova higiene do corpo responsabilizava o indivíduo de modo a desenvolver uma consciência de bem-estar coletivo, enquanto a Educação Física ${ }^{2}$ voltava-se para obtenção de indivíduos equilibrados e autossuficientes. As teorias eugênicas, por sua vez, buscavam argumentar que, com a disciplina dos músculos, se aperfeiçoaria a disciplina das vontades (LenHARO, 1986; SiLVA, 2008).

O tema do esporte assumiu uma relevância particular no interior do discurso escrito ou figurativo do fascismo. É notória a importância que, especialmente no decorrer da década de 30, a política de massas do regime atribuiu ao esporte enquanto fator de enquadramento e de formação do italiano do futuro. $\mathrm{O}$ esporte tornou-se sinônimo de estilo de vida, "modo fascista de conceber e de levar a vida [...], de formar o caráter fascista" (MALVANO, 1996, p.268). A ideia do jovem atleta era posta a representar a força, a vitória não só do atleta, mas também do próprio regime.

A Ação Integralista Brasileira (AIB) - movimento social que emerge no Brasil Republicano, arquitetado por Plínio Salgado - não ficou à parte dessas questôes e buscou formar - inspirado no fascismo italiano, nos discursos médicos eugênicos e de fundamentação cristã do período - seus "soldados" para a defesa da Nação do ponto de vista "moral, intelectual e físico". O integralismo deu visibilidade a esse investimento, seja na divulgação de impressos imbuídos do objetivo de normatizar a prática esportiva, seja naqueles voltados à divulgação dessa prática corporal.

O integralismo, que emergiu no cenário político na década de 30 do século XX como o primeiro movimento político de massas do país, possuía núcleos 
organizados em todo território nacional, contando, em 1937, com mais de um milhão de membros inscritos em suas fileiras ${ }^{3}$. O discurso integralista se propagou de modo surpreendente e angariou adeptos em diferentes classes sociais, o que possibilitou que a AIB criasse escolas; fundasse ambulatórios e lactários; elegesse vereadores, prefeitos e deputados integralistas, atuando nos meios políticos como partido; que elaborasse, através de seus militantes, inúmeras obras doutrinárias; que criasse cursos de enfermagem, puericultura, Educação Física, entre outros; que promovesse inúmeras reuniōes doutrinárias, passeatas, congressos, seminários e eventos que tornaram públicos sua popularidade e alcance doutrinário.

A expressividade do movimento também pode ser observada por intermédio dos jornais. Ao todo foram criados mais de cem diferentes jornais publicados em cidades do Rio Grande do Sul, São Paulo, Minas Gerais, Sergipe, Alagoas, Paraná, Pernambuco, Rio de Janeiro, Bahia, Santa Catarina, Maranhão, Amazonas, Espírito Santo, Goiás, Ceará, além das obras e enciclopédias que orientavam os membros do movimento sobre o comportamento e comprometimento a ser assumido pelos integralistas na construção da "pátria integral".

Considerando a expressividade da AIB no cenário político da época, esta pesquisa analisa a educação do corpo $^{4}$ por meio da Educação Física e dos esportes, de homens e mulheres membros das fileiras integralistas no período de 1932 a 1938. Procuramos compreender os preceitos da "educação do corpo integralista" elaborada pelo movimento cuja finalidade primeira era educar, disciplinar e preparar seus membros tornando-os "soldados obstinados a defender a nação" (A OFFENSIVA, ano I, n.26, p.2, 8 nov. 1934).

Nesse sentido, ganham destaque os escritos de Hollanda Loyola, Mestre de Campo da Milícia no
Distrito Federal (RJ) e diretor da Escola Technica de Instructores de Educação Física integralista, porque instituíram um modo inovador de conceber a prática esportiva e o treinamento físico. Loyola, renomado autor da Educação Física em âmbito nacional, foi editor e diretor do primeiro periódico específico da área, Revista Educação Physica (a partir de 1939), colaborador na constituição de métodos e programas de Educação Física e autor de17 livros publicados pela Companhia Brasil Editora. Ao ingressar para os quadros da AIB, Loyola redigiu vários artigos e crônicas sobre Educação Física e esportes para os jornais integralistas os quais circularam durante todo o período de legalidade do movimento.

Além de sua participação na Revista Educação Physica e nos quadros da AIB, Loyola atuou como inspetor de Educação Física do Ministério da Educação e Saúde (MEC), presidente do Departamento de Educação Física Superior da Associação Brasileira de Educação Física (ABEF) ${ }^{5}$ e diretor do Departamento de Educação Física da Universidade da Capital Federal. Sua vida e obra foram interrompidas em função de uma enfermidade e morte prematura em 1944. Contudo, apesar do curto período de tempo em que atuou na área, tornou-se uma referência importante para a Educação Física na transição dos anos de 1930 para os anos de 1940, não só para a AIB como para a consolidação da área em diferentes campos da sociedade brasileira.

Desse modo, direcionar olhares para os escritos de Loyola, nos impressos integralistas, se justifica não só por possibilitar um maior entendimento sobre o papel atribuído à Educação Física e aos esportes por esse movimento específico, mas, sobretudo, por revelar uma faceta pouco conhecida de Hollanda Loyola: sua intensa atuação junto AIB e as prescrições propostas para a educação de adeptos do integralismo.

\section{Metodologia}

Esta pesquisa de cunho qualitativo apresenta como recorte temporal o período de 1932 a 1938, cuja delimitação emerge do próprio objeto de estudo, uma vez que 1932 é o ano de fundação da Ação Integralista Brasileira e, 1938, o ano de extinção da Associação Brasileira de Cultura (ABC), antiga AIB. Vale lembrar que no início do Governo ditatorial de Getúlio Vargas, em 1937, todos os partidos políticos foram suprimidos, juntamente com eles a AIB, o que demandou uma readaptação das suas funçôes, levando-a a se transformar em sociedade civil com a denominação de Associação
Brasileira de Cultura. Como ABC, funcionou até 1938 quando foi completamente extinta e seus líderes foram enviados para o exílio.

Para realização desta pesquisa, tomamos como fonte primária números do jornal $A$ Offensiva, periódico doutrinário e prescritivo do movimento, que se encontram no Acervo Plínio Salgado do Arquivo Público e Histórico do Município de Rio Claro - SP e os arquivados na Biblioteca Nacional - RJ. A seleção do material deu-se a partir do contato com diversos documentos, jornais, cartas, 
manuais didáticos, regimentos, enciclopédias e livros integralistas, e a opção por $A$ Offensiva deve-se à grande quantidade de artigos e colunas sobre esportes e Educação Física publicados nesse periódico.

A Offensiva, órgão oficioso e de circulação nacional, foi utilizado pela AIB para fazer chegar aos mais distantes núcleos e militantes novidades sobre suas atividades e realizaçōes e para transmitir/popularizar sua doutrina. Os congressos, passeatas, cursos, festas pelas datas comemorativas recebiam lugar de destaque nos periódicos do movimento.

O integralismo concebia o jornal como instrumento de educação para a população "menos culta". Aos mais cultos, considerados mais aptos para compreensão da doutrina, a abordagem deveria ser feita por meio dos livros. Aos intelectuais cabia o papel de educar "as massas", de preparar a doutrina e transmitila ao povo. Era deles o dever de escrever para o jornal.

Uma das preocupaçōes que regia a forma tipográfica do jornal integralista diz respeito ao modo de divulgação da doutrina. Havia a preocupação de que a doutrina fosse transmitida aos militantes de modo uniforme, de que os jornais do interior, aqueles que chegavam até o militante mais distante, fossem organizados de modo a reproduzir os jornais maiores, editados nos grandes centros onde se concentrava a elite dirigente do movimento. No caso, São Paulo e Rio de Janeiro.

O Jornal $A$ Offensiva foi lançado na cidade do Rio de Janeiro em 17 de maio de 1934 e extinto em 19 de março de 1938. Sua tiragem era semanal, de maio de 1934 a janeiro de 1936, e suas vendas somente por assinatura. A partir de 28 de janeiro de 1936, tornou-se diário matutino mantendo a distribuição por assinaturas e ampliando sua vendagem por intermédio das bancas. Dos 748 exemplares que foram publicados entre 17/05/1934 e 19/03/1938, analisamos artigos, seções, colunas e pequenas notas. Desse montante, consoante aos objetivos propostos para a elaboração da pesquisa, selecionamos os textos que traziam informaçōes sobre a educação do corpo por meio da Educação Física e dos esportes, com destaque para os artigos de Loyola, 26 ao todo.

Além dos artigos de Loyola, publicados de maio de 1935 a fevereiro de 1936, analisamos a seção
"Chronica do Dia", redigida também por Loyola e veiculada diariamente em $A$ Offensiva, de fevereiro de 1936 a março de 1938. Esse material, além das notas soltas pelos jornais, compõe o conjunto documental interpretativo empregado nesta pesquisa e, ainda que um ou outro texto tenha sido utilizado de modo menos direto, cada um deles tornou-se fundamental para compreensão sobre o conjunto discursivo produzido por Loyola para a AIB no período.

Como ferramenta metodológica foi utilizada a análise de conteúdo (BARDIN, 1988) a partir de três fases distintas: a pré-análise, na qual foi realizada a organização do material empírico, no caso, os documentos produzidos por Loyola para o jornal A Offensiva. Nesse momento foram sistematizados todos aqueles que se relacionam com a educação do corpo por meio da Educação Física e do esporte. Posteriormente foi realizada a exploração desse material, caracterizada pela codificação a partir das unidades de registro. Desse procedimento resultou a etapa de tratamento dos dados que foram categorizados e interpretados considerando-se os objetivos da pesquisa.

Dessa catalogação e do entrecruzamento entre as diferentes fontes de pesquisa foram elaboradas unidades de significado que possibilitaram melhor compreender as ações empreendidas pela AIB para arquitetar uma "retórica corporal", tendo como "lócus" privilegiado as prescrições advogadas por Hollanda Loyola no que tange à disciplinarização dos militantes inscritos nas fileiras integralistas.

As unidades de significados nos auxiliaram a classificar, reunir e agrupar o material encontrado de acordo com a temática relacionada ao corpo e à educação do corpo em $A$ Offensiva. Temas como eugenia, higiene, disciplinamento corporal através da Milícia Integralista, educação paramilitar, Educação Física, esportes, entre outros, nos possibilitaram uma seleção do que enfocaríamos para concretização deste estudo. Os escritos de Loyola foram selecionados a partir dessas unidades de significados e, por ora, optou-se pela análise dos textos que abordam, de modo mais específico, os esportes e a Educação Física, temas enfaticamente tratados por Loyola no periódico da AIB. 


\section{Apresentação e discussão dos resultados}

\section{A educação do corpo no integralismo}

A ideia de "educação integral para o homem integral" apresentava-se como uma constante do discurso pliniano. Salgado, Chefe Nacional e supremo da AIB, eleito por plebiscito, ao discursar sobre a formação do integralista, afirmou que o verdadeiro ideal educativo é o que se propõe a educar o homem todo, ou seja, o conjunto do homem físico, intelectual, cívico e espiritual. Nessa perspectiva, a educação integral precisaria evitar a "unilateralidade dos sistemas educacionais" que fazem predominar o âmbito esportivo, o científico, entre outros. Essa preocupação foi observada em escritos de outros dirigentes e intelectuais integralistas (CORBISIER, 1959; Dias, 1959; Penna, 1959; Salgado, 1959) quando chamam a atenção para a educação que, segundo eles, não poderia negligenciar nenhuma de suas facetas, fosse a física, a científica, a artística, a econômica, a social, a política e/ou a religiosa. Argumentava-se em prol da formação/doutrinamento do militante através de um conjunto pedagógico que incluía os aspectos moral, intelectual e físico.

Em juramento prestado aos quadros da AIB no dia 20 de dezembro de 1934, o Chefe Nacional destacou o que se poderia esperar do integralismo no âmbito do corpo: "como cultura physica, o integralismo age no sentido de dotar os 'camisas-verdes' ${ }^{6}$ não somente de uma consciência sanitária, mas de uma capacidade de luta, para o que mantém a instrucção militar e o cultivo dos esportes athleticos" (SALGADO, 1934, p.1). Por meio de um discurso apreciativo dos esportes eram veiculados valores como a exaltação da presteza física e da autodisciplina e formava-se o "camisa-verde" "forte de físico e de espírito", atingindo a educação seus fins morais, doutrinários e eugênicos (A Offensiva, p.6, 8 nov. 1934).

Através do esporte, esperava-se regenerar física e moralmente a raça. A rapidez, a eficiência, a boa forma física que estavam na base do mito esportivo podiam tornar-se suportes eficazes para designar, assim como o "Jovem Estado Fascista', dinâmico e moderno", o Jovem Estado Integralista de ideias novas e apto a salvar a Nação (Malvano, 1996, p.67).

Vale lembrar que esse era um pensamento recorrente da época, portanto, não estava restrito aos quadros da AIB. A educação do corpo era reconhecida como essencial para o desenvolvimento da Nação, pois ao modelar os corpos físicos, remodelaria o corpo social pelo revigoramento orgânico capaz de legar robustez e integridade às gerações futuras (GoELLNER \& Fraga, 2003; Góis Junior \& Lovisolo, 2005). Nessa perspectiva, Fernando de AzEvEDo, eminente intelectual do período, afirmava que

Uma vez introduzida pela educação nos habitos do paiz, a pratica desta cultura physica sustentada durante uma larga serie de geraçôes, depuraria a nossa raça de diatheses morbidas, locupletandoa, progressivamente, pela creação incessante de individuos robustos. Os mortos governam os vivos. As gerações de amanhã apuradas, por systema, pela educação physica - afinadora da raça e collaboradora do progresso - imprimiriam assim, nas que lhes succedessem, o cenho de seu caracter, para que pudessem, com o augmento do patrimonio biologico hereditario, aperfeiçoar ainda mais a natureza humana (1920, p.229).

Compartilhando de tais preceitos, o integralismo defendia que o esporte deveria ser praticado por pessoas de todas as idades, raças, etnias e classes sociais. Partia-se do pressuposto de que o homem ideal seria forte física e intelectualmente, sendo necessária a prática esportiva cuja realização voltava-se, também, para higienização corporal.

A Educação Física, por sua vez, deveria cumprir o papel de corrigir os corpos defeituosos, raquíticos e deformados, formando homens e mulheres saudáveis fisicamente. Essas qualidades eram vistas como fundamentais ao soldado que se pretendia formar para defesa da "Nação Integral". Para além de capacitar organicamente os corpos, a Educação Física era aplicada com a finalidade de disciplinar os quadros integralistas e de militarizar seus membros para torná-los "soldados" obstinados a defender a Pátria e a lutar pelos ideais integralistas. O "soldado-integral" deveria ser treinado moral, intelectual e, sobretudo, fisicamente tornandose apto para agir com prontidão quando fosse convocado, demonstrando total obediência aos dirigentes do movimento e à estrutura hierárquica da AIB.

Plínio Salgado defendia uma revolução desarmada para o Brasil, mas não deixava de registrar que, havendo necessidade, o membro da fileira integralista deveria estar preparado, física e mentalmente, para sair às ruas e lutar. À Educação Física cabia o papel de preparar o militante para assumir seu posto na revolução armada, caso a AIB não atingisse os objetivos almejados por meio da "Revolução Espiritual", ação que se comprometia levar a cabo. Nesse contexto, a Educação Física integralista assumia uma função militarizante, devendo com ela também se preocupar. 


\section{Hollanda Loyola e a Educação Física na AIB}

Para coordenar os trabalhos da Milícia no Distrito Federal, o Chefe Nacional comissionou Francisco de Assis Hollanda Loyola ao posto de Mestre de Campo, determinando a todos os integralistas que viessem a essa patente que a reconhecessem e lhe prestassem as devidas honras. Loyola ocupou este cargo até 4 abril de 1935 quando a Milícia foi extinta em cumprimento a Lei de Segurança Nacional, que definia os crimes contra a ordem política e social e conferia ao Governo Federal poderes especiais para reprimir atividades políticas ditas subversivas.

No entanto, em 1936, a estrutura da Milícia foi transplantada para a organização da juventude integralista denominada de "Plinianos", momento no qual se transformou em Secretaria Nacional de Educação (moral, cívica e física), cuja missão era prosseguir com o trabalho de organização e disciplinamento. Nessa unidade, Loyola passou a ocupar o cargo de Secretário Provincial de Educação e iniciou a publicação de uma série de artigos "technicos sobre Educação Physica, com a finalidade de orientar as atividades dos soldados do Sigma" (Monitor Integralista, ano V, p.3, 10 abr. 1937).

Ao longo do período no qual atuou na AIB, Loyola tornou-se o escritor que publicou o maior número de textos sobre Educação Física e esportes em $A$ Offensi$v a$ tendo, inclusive, assinado uma coluna específica, denominada "Chronica do dia". Da leitura atenta dos seus escritos nesse jornal podemos afirmar que Loyola buscou elaborar, para o Brasil, o que nomeou de "Plano Geral" de Educação Física, pois abrangia não só um método, mas um conjunto deles. Sua inspiração adveio de estudos que realizou sobre planos de Educação Física desenvolvidos em outros países.

$\mathrm{O}$ autor compreendia a necessidade do investimento em uma Educação Física ${ }^{7}$ que fosse planejada e estruturada para o povo brasileiro, considerando as especificidades de clima e costumes que eram diferentes dos europeus e norte-americanos. Nesse sentido, propunha uma "colaboração integralista", direcionada para a elaboração e efetivação de um plano nacional de Educação Física que visasse, de fato, o melhoramento da raça brasileira.

Seguindo os princípios doutrinários de melhoramento da raça, Hollanda Loyola buscou justificar e apresentar, no jornal $A$ Offensiva, por intermédio de um conjunto de artigos publicados sequencialmente, sua proposta de se pensar em uma Educação Física única que auxiliaria no fortalecimento da Nação.

\begin{abstract}
Das columnas de A OFFENSIVA queremos prestar a realização effectiva e util de um plano nacional de educação physica que vise de facto o melhoramento de nossa raça. [Em] artigos de ordem technica [...] estudaremos a educação physica, seus methodos e sua aplicação, esboçaremos o nosso plano em funcção do nosso clima, do nosso povo e de nossa formação política, de fórma a ser alcançado por todos aquelles que, tendo uma superior concepção de patriotismo, se interessam pela solução dos graves problemas de nossa nacionalidade. Cremos contar com a comprehensão de todos, porque só pela fortaleza da raça será o Brasil grande e forte! (Loyola, 1935b, p.4).
\end{abstract}

Nos seus escritos, Loyola elenca vários fins para a Educação Física nacional, sendo o primeiro deles considerado como corretivo, pois, por meio de exercícios específicos, esperava-se que a Educação Física corrigisse deficiências dos aparelhos respiratório, circulatório e digestivo, da coluna tais como cifose, lordose e escoliose. Como segunda finalidade, o autor destaca a atuação da Educação Física na adaptação do organismo de modo a prepará-lo para vida, de trabalhá-lo para a obtenção de saúde, da força e da resistência. Por fim, indica a ação da Educação Física na formação moral do indivíduo, por meio da associação da aptidão física ao desenvolvimento físico, agindo para a aquisição das qualidades morais superiores (Loyola, 1935e).

A importância conferida por Loyola à Educação Física é explicitada no artigo "Educação Physica: finalidades", publicado em $A$ Offensiva de 8 de junho de 1935, quando argumenta que é da Educação Física "[...] a função de preparar para vida, de dar normalidade e capacidade às funções orgânicas, tonicidade aos músculos, resistência ao esqueleto, flexibilidade às articulações, controle ao sistema nervoso" (Loyola, 1935e, p.6).

Resultante de seus escritos e prescrições, ancorada na ideia de que o exercício físico trazia muitos benefícios aos seus praticantes, a AIB promoveu uma campanha para propagar a Educação Física, generalizar seus conhecimentos e identificá-la com hábitos do povo, tendo Loyola como seu principal porta-voz. Tal investimento estava fundamentado na percepção da prática de Educação Física específica para cada fase da vida, com finalidades distintas que deveriam ser respeitadas a fim de se alcançar um maior rendimento sem exigir demais e sem prejudicar o corpo do praticante ou mesmo desestimulálo, o que, para Loyola, contrariaria as finalidades maiores dessa atividade. Desse modo, prescrevia um 
tipo determinado de exercício físico, considerando aspectos anatômicos e fisiológicos dos indivíduos.

Os fins eugênicos e higiênicos eram especialmente visados pela AIB que esperava cultivar, por meio dos esportes, corpos saudáveis e disseminar preceitos de higiene individual e coletivos extensivos às famílias. O aperfeiçoamento eugênico, alicerçando-se no aprimoramento do físico, era compreendido como o promotor do afastamento dos vícios da raça e o aprimoramento higiênico o promotor dos corpos saudáveis que iriam salvar o Brasil.

Segundo Goellner e Fraga

Nos primeiros anos do século XX, a constituição homogênea do povo brasileiro passou a ser o pilar fundamental de um projeto de humanidade centrado na eliminação de tudo aquilo corporalmente inominável. O disciplinamento e a crença na transformação da sociedade através da padronização do corpo brasileiro se tornaram mais sofisticados ao ganharem contornos científicos mais 'apurados'. Buscando modelar os corpos físicos, a eugenia remodelaria o corpo social pelo revigoramento orgânico e pela instauração de uma 'consciência' no cidadão e a higiene asseguraria aos brasileiros e brasileiras uma condição física e moral capaz de legar robustez e integridade às geraçóes futuras (2003, p.61).

Ou seja, os benefícios alcançados pelo exercício físico não visavam apenas resultados imediatos: eles reverberariam nas gerações futuras tornando evidentes os pressupostos da ciência eugênica ${ }^{8}$. Nesse sentido, o integralismo defende que os fortes descendem dos fortes. Para Loyola, esse dom da Educação Física é o mais valioso de todo o seu alcance, sua influência eugênica, influência essa que, segundo ele, não pode ser obtida apenas por práticas empíricas e processos teóricos (LoYolA, 1935e, p.6).

A orientação era para que o povo de todas as idades e de todas as camadas sociais buscasse compreender a Educação Física e a praticasse dentro de um regime metódico, científico, racional; que o jovem procurasse entender melhor a finalidade da Educação Física nos seus "resultados psychicos e physiologicos"; que o esporte fosse praticado como um aperfeiçoamento das qualidades morais, como elemento de aproximação social e, como tal, "praticado dentro das normas científicas traçadas pelo médico" (LoyOLA, 1935b, p.4).

A proposta da Educação Física para "todos" deveria estar fundamentada nos princípios mais nobres dessa prática:

Vamos aos clubs, às sociedades sportivas, preguemos o sport, não como uma profissão, como um motivo de exhibição pessoal, como um processo de mercantilização, mas como uma bella e empolgante realização de força e de saúde, de beleza e de esthetica. [...] Mostremos a todos, expliquemos a todos o objectivo da educação physica, seu alcance physiologico, moral e social, sua finalidade hygienica, eugênica e esthetica, suas bases racionaes, scientificas, fundamentadas (LOyOla, 1935a, p.6).

Era função da Divisão de Cultura Physica orientar os integralistas sobre o desenvolvimento físico, mantendo aulas de ginástica e promovendo a prática de esportes apropriados para cada sexo e idade. $\mathrm{Na}$ seção "Movimento Integralista", as mulheres também eram convidadas para integrar o Curso de Educação Physica oferecido por essa divisão (Movimento Integralista, $A$ Offensiva, ano III, n.150, p.9, 8 abr. 1936).

Contudo, as atividades esportivas indicadas a homens e mulheres eram distintas pelo sexo. Aos homens interessava a "combatividade, a força, a disciplina, necessárias para o amoldamento a certos conceitos de conduta, a certas normas de disciplina social, mais rígidas em sua apreensão" (LOYOLA, 1935f, p.5). Às mulheres eram recomendadas apenas as práticas esportivas que não viessem a comprometer a sua feminilidade e lhe preservassem a fertilidade.

Essa distinção educacional entre sexos também não estava isolada do que se propagava na época. Segundo Fernando de Azevedo,

O que é preciso, no entanto, ter sempre em vista na Educação Física é a diferença do sexo... Os órgãos de agressão e defesa no homem reclamam violência de movimento, na mulher apenas gestos suaves, a quase quietude. [...] A violência e o exercício no homem criam as asperezas da superfície do corpo pelo desenvolvimento de ossos e músculos. A maternidade ou a sua predestinação avoluma as formas do ventre, nos seios e nos membros inferiores (1939, p.94).

Ou seja, havia diferentes atribuições conferidas aos brasileiros e às brasileiras no tocante a suas contribuições para o fortalecimento da raça e, por consequência, da Nação. A ênfase dada à feminilidade e à maternidade se justificava porque ser mãe era considerada a mais sublime missão da mulher. Uma habilidade natural, essencial e inevitável.

Para Loyola, a Educação Física destinada aos homens e mulheres integralistas se confirmaria diante da realização do exercício físico. Assim, explicita alguns conceitos com o intuito de elucidar aos leitores algumas nomenclaturas que figuram em seus textos e em outros cujo enfoque é a Educação 
Física e o esporte. Ao conceituar "Educação Physica", "gymnastica" e "cultura physica", afirma que a "Educação Physica" tem uma significação mais própria e dá ao exercício físico a importância que de fato lhe compete dentro da educação geral. Para tecer tal argumento, recorre ao General Amoros, um dos fundadores da escola de ginástica francesa ${ }^{9}$, quando aponta que "[...] a educação physica é a sciencia povoada dos movimentos e de suas relações com os nossos sentidos, nossa intelligencia, nossos sentimentos, nossos costumes e o desenvolvimento de todas as nossas faculdades" (Loyola, 1935e, p.6). Segundo Loyola a "Educação Physica" tem um sentido e significado mais amplo que

[...] integra os exercícios physicos na educação geral do individuo, a qual não póde faltar o concurso da saúde, da integridade dos órgãos e do equilíbrio orgânico [...]. Nem gymnastica, nem cultura physica, mas educação physica - preparação, adaptação, correcção e utilização dos elementos physicos para a formação physica e consequentemente preparo intelectual e equilíbrio moral; fazer do corpo o que recommendava Augusto Comte - o pedestal do cérebro (LOYOLA, 1935c, p.6).

Ao transpor essa discussão para o território nacional defende a necessidade de uma educação geral para o povo brasileiro, a fim de desenvolver suas faculdades físicas, intelectuais e morais, porque, ainda que fosse novo e de raça confusa "está fadado a desempenhar um grande papel na história continental". A Educação Física, portanto, deve "orientá-lo para a realização do homem integral - forte de physico, culto de cérebro, grande de alma” (LOYOLA, 1935e, p.6).

O autor fazia questão, ainda, de distinguir a Educação Física do esporte, sendo o segundo consequência da primeira. O esporte, explica, é o resultado de uma "applicação judiciosa", o seu "coroamento", mas nunca a própria Educação Física: "os sports fazem parte integrante da Educação Physica, [...] mas não constituem a própria Educação Physica porque aquelles requerem do praticante um máximo de energia e destreza, predicados esses adquiridos pela prática judiciosa da Educação Physica" (LoYola, 1935d, p.6).

No que se refere à Educação Física, Loyola identificou, em matéria publicada em $A$ Offensiva datada de 18 de maio de 1935, alguns dos principais problemas que assolavam a área no Brasil da década de 30. Para tanto, recorreu a um estudo que desenvolveu acerca dos métodos de ensino mais utilizados no país. Por entender ser necessário um método que colaborasse para o sentimento do espírito nacionalista, tão comum nesse período, criticou enfaticamente a heterogeneidade de princípios e a diversidade de doutrinas, o que, em sua compreensão, seria prejudicial à formação de uma nacionalidade coesa e indivisível, "[...] principalmente quando essa nacionalidade só tem a favor de sua unidade, cohesão, indivisibilidade e [...] a boa vontade, o patriotismo e a grandeza moral do povo brasileiro, simples e bom, heróico e anônimo" (p.4).

Opondo-se à importação de métodos e entusiasmado pelas ideias nacionalistas em voga no período, difundidas com fervor pela AIB, Loyola defendia um método que fosse elaborado com base no modo de vida do povo brasileiro, criticando a confusão de métodos advindos de diversos países do mundo e que não correspondiam, segundo ele, aos interesses e necessidades da nacionalidade brasileira. Nesse sentido, advertia o autor: "a Educação Physica é universal e como tal deve estar sempre subordinada às condiçôes mesológicas do povo que a pratica: o contrário é absurdo, irracional" (LoYola, 1935b, p.4).

Loyola argumentava que faltava "methodizar, racionalizar e integrar a Educação Physica no plano geral de Educação com o objectivo superior de melhorar a raça, fortalecel-a, engrandecel-a", pois "só uma nação forte pela cultura e forte pela raça será capaz de impor a sua soberania, manter a sua independência, fazer respeitar a sua integridade" (LOYOlA, 1935b, p.4).

Para atender a tal demanda, buscou elaborar um "Plano Geral" a ser aplicado para o Brasil e, consequentemente, para o soldado integralista. Nas várias edições de $A$ Offensiva em que menciona esse tema, recorre ao mesmo argumento: esse plano não comporta um só método, mas um conjunto deles. $\mathrm{O}$ autor destaca que o Brasil viveu, durante o Império, o esquecimento de uma parte basilar da educação, a Educação Física, devendo ser, no novo regime, a República, muito maior o investimento nessa área. Caberia, portanto, o investimento na Educação Física planejada e estruturada para o povo brasileiro, direcionado, sobretudo, para o fortalecimento do espírito nacionalista visando à unidade da Pátria.

Para além da estruturação desse plano, Loyola identificava nos esportes um meio para a educação do corpo integralista, mostrando-se favorável a sua aplicação nas fileiras da AIB. Compreendia que o atleta, insistindo na prática perseverante e metódica do esporte que melhor se adapta à sua constituição e às suas possibilidades físicas, adquire com mais rapidez automatismo, destreza, resistência (LoYOLA, 1936).

Os esportes nesse período estavam em plena expansão no território nacional, fulgurando em 
várias cidades e conferindo novos ares à dinâmica social. Segundo Melo (2010, p.14), no Brasil, desde o quartel final do século XIX se "observará um aumento da presença social do esporte, do número de modalidades e o estabelecimento de novos sentidos e significados para prática esportiva, relacionado à mudança na sociedade brasileira, que ansiava a se inserir na modernidade". Tal entusiasmo se refletia em $A$ Offensiva que destinava espaço em suas páginas para divulgar e incentivar a adesão às práticas esportivas, em especial, nas seções denominadas "Turf”, "A Offensiva sportiva", "No Sport", nas quais eram noticiados os acontecimentos esportivos no Brasil e

\section{Considerações finais}

A Ação Integralista Brasileira utilizou amplamente os impressos para propagar seus ideais de corpo e educar corporalmente homens e mulheres, seja através da Educação Física, seja através do esporte, ou ainda por outros meios, tornando-os membros dispostos a defender suas causas. Nesse sentido, Hollanda Loyola trouxe expressivas contribuições para o movimento, acumulando uma vasta e rica produção veiculada amplamente em $A$ Offensiva.

Influenciado pelas discussões ocorrentes no Brasil na década de 30 , em que os discursos em voga apontavam para incrementos no melhoramento da raça, da higiene e da eugenia, Loyola produziu textos que ganharam importância em periódicos da $\mathrm{AIB}$ em função do que difundiam sobre a moralização e formação da raça forte, conquistas alcançadas, segundo os escritos, através da Educação Física e esportes.

Nesse sentido, é importante enfatizar que a compreensão que Hollanda Loyola tinha da Educação no mundo, conferindo visibilidade a modalidades e competições. Loyola era um de seus divulgadores.

A Educação Física e o esporte, portanto, foram identificados pela AIB como meios de educação do corpo de homens e mulheres adeptos do integralismo. Se por um lado sua prática colaborava para a adesão à AIB, por outro resultava no fortalecimento orgânico dos corpos, tão necessários para evitar o enfraquecimento e a degeneração. Por tal razão, $A$ Offensiva, através das palavras de Hollanda Loyola, insiste na relevância da Educação Física como tratamento dos males do corpo e, consequentemente, da Pátria em formação.

Física e recomendações para sua prática dentro do movimento integralista não eram distantes do que se vivenciava na Educação Física brasileira. Inclusive porque o próprio Loyola era um de seus protagonistas: o caráter eugênico e higiênico, a distinção entre os sexos, o papel do esporte na constituição de um homem forte física e moralmente estavam presentes nos seus escritos dentro e fora de $A$ Offensiva. No entanto, o reforço aos preceitos integralistas e a defesa indelével das ideias de Plínio Salgado demonstravam uma particularidade, qual seja: a compreensão de que a educação do corpo poderia doutrinar os militantes das fileiras da AIB e arregimentar novos adeptos, preparando-os, inclusive, para a luta armada.

Enfim, ao agregar as prescriçóes de Hollanda Loyola a todas as suas práticas ritualistas e simbólicas, o integralismo impunha ao corpo um modo muito próprio e uno de ser integralista, modo de ser de um "soldado-integral".

\section{Notas}

1. Este estudo recebeu apoio da Fundação de Amparo a Pesquisa de São Paulo/FAPESP para o seu desenvolvimento. Não houve conflitos de interesses para realização do presente estudo.

2. Optamos por utilizar o termo Educação Física com iniciais em maiúsculo assim como o fez Hollanda Loyola em seus artigos.

3. Não há documentações de cunho historiográfico em relação ao número de filiados na AIB, dessa forma, seguiu-se a contabilidade oficial do movimento, divulgada no jornal Monitor Integralista, mesmo sabendo da dificuldade historiográfica em adotar como base analítica o discurso oficial de uma doutrina política.

4. O termo é aqui compreendido em consonância com as afirmaçôes de SOARES (2006, p.xi) para quem os corpos podem "traduzir, revelar, evidenciar formas bem precisas de educação, modos bastante sutis de inserção de indivíduos e grupos em uma dada sociedade, formas múltiplas de socialização".

5. A ABEF, "sociedade civil de caráter nacional com sede e foro no Distrito Federal", foi fundada em 1941 "por elementos especializados e interessados em Educação Física” (Artigo 1º). 
6. Os membros inscritos nas fileiras integralistas eram chamados de "camisas-verdes" em função do uniforme composto por camisa na cor verde que deveriam usar em todas as aparições públicas do movimento.

7. Nos textos que tratam da educação física e dos esportes veiculados nos jornais integralistas, inclusive nos textos de Hollanda Loyola publicados em A Offensiva, não foi possível observar distinções entre os termos "exercício", "exercício físico", "atividade física", "atividade corporal”. Educação Physica, por sua vez, não aparece como área disciplinar. O termo está muito mais próximo de designar "exercício physico", tanto que Loyola utiliza trechos de um de seus artigos para distingui-lo de "gymnastica" e "cultura physica" argumentando que seu esforço representa uma tentativa de buscar esclarecer qual deles melhor designa exercício físico e mais convém à "pedagogia nacional”.

8. Concebida como sinônimo de modernidade e progresso, a Eugenia, gestada em meados do século XIX por Francis Galton, era uma Ciência nova que despertava certo fascinio em meio à intelectualidade da época. Com o objetivo de melhoria da espécie, via reprodução, seus mecanismos eram baseados na ordenação e classificação dos individuos, visando ao incentivo da procriação dos seres mais bem dotados, restringindo a proliferação de "degenerados". No Brasil, nos primeiros anos do século XX, foi identificada como mais um saber legítimo que auxiliaria a civilizar, limpar e aperfeiçoar a heterogênea população brasileira (SILVA, 2008).

9. Sobre esse tema ler GoelLner (1992).

\begin{abstract}
Physical Education and sports in Ação Integralista Brasileira: Hollanda Loyola and body education

TIt investigates how Ação Integralista Brasileira, a social movement that emerged in Republican Brazil, educated physically, through of Physical Education and sports, members enrolled in its ranks. It examines articles published in A Offensiva, prescriptive and doctrinaire newspaper of the movement, published from 17/05/1934 to 19/03/1938, with emphasis on Francisco de Assis Hollanda Loyola's articles. Loyola was Master of the Militia Field and director of the integralist Physical Education School of Instructors, and his writings are highlighted because they have established an innovative way to conceive the sports and physical training at AIB. Loyola won space in the newspaper and traced "General Plan" of Physical Education focused on Brazilian people's needs and characteristics, an aspect emphasized by the author. The study concluded that adding Loyola's requirements to ritualistic and symbolic practices, the 'integralismo' imposed on the body a way of being integralist, way of being an "integral soldier".
\end{abstract}

Uniterms: Physical education; Ação Integralista Brasileira; Hollanda Loyola.

\title{
Resumen
}

Educación Física y deporte en Acción Integralista Brasileña: Hollanda Loyola y educación del cuerpo

Investiga cómo la Acción Integralista Brasileña, movimiento social que surgió en el Brasil Republicano, había educado el cuerpo, a través de la Educación Física y los deportes, de los miembros inscriptos en sus filas. Analiza los artículos publicados en A Offensiva, periódico doctrinario y prescriptivo del movimiento, publicado de 17/05/1934 al 19/03/1938, con énfasis en los artículos de Francisco de Assis Hollanda Loyola. Los escritos de Loyola, Jefe de Campo de la Milicia y director de la Escuela de Instructores de Educación Física integralista, se destacan porque han establecido una forma innovadora de concebir el deporte y el entrenamiento físico en la AIB. Loyola ganó espacio en el periódico y trazó el "Plan General" de Educación Física centrado en las necesidades y características del pueblo brasileño, aspecto subrayado por el autor. Se concluyó que al agregar las directrices de Loyola a las prácticas rituales y simbólicas, el integralismo tenía impuesto sobre el cuerpo una manera muy propia de ser integralista, manera de ser un "soldado-integral"..

Palabras Clave: Educación física; Acción Integralista Brasileña; Hollanda Loyola. 


\section{Referências}

A OFFENSIVA. Rio de Janeiro, ano I, n.26, p.2, 6, 8 nov. 1934. . Rio de Janeiro, ano III, n.150, p.9, 8 abr. 1936.

AZEVEDO, F. A regeneração racial pela educação physica. Revista Educação Physica, Rio de Janeiro, n.8, p.8-12, 1939. . Da educação physica. São Paulo: Weiszflog Irmãos, 1920.

BARDIN, L. Análise de conteúdo. Lisboa: Ediçōes 70, 1988.

CORBISIER, M.C.A. Integralismo e educação do feminino. In: SALGADO, P. (Org.). Enciclopédia do integralismo. Rio de Janeiro: Clássica Brasileira, 1959. v.9, p.63-9.

DIAS, C.P. A mulher e o integralismo. In: SALGADO, P. (Org.). Enciclopédia do integralismo. Rio de Janeiro: Clássica Brasileira, 1959. v.9, p.81-93.

GOELLNER, S.V. O método francês no Brasil: da caserna à escola. 1992. 215f. Dissertação (Mestrado em Educação) Universidade Estadual de Campinas, Campinas, 1992.

GOELLNER, S.V.; FRAGA, A.B. Antinous e Sandwina: encontros e desencontros na educação dos corpos brasileiros. Movimento, Porto Alegre, v.9, n.3, p.59-82, 2003.

GOIS JUNIOR, E.; LOVISOLO, H.R. A educação física e concepçōes higienistas sobre raça: uma reinterpretação histórica da educação física brasileira dos anos de 1930. Revista Portuguesa de Ciências do Desporto, Porto, v.5, n.3, p.322-8, 2005. LENHARO, A. Sacralização da política. 2. ed. São Paulo: Papirus, 1986.

LOYOLA, H. Chronica do dia: especialização. A Offensiva, Rio de Janeiro, ano III, n. 98, p. 7, 6 jan. 1936. . Considerações gerais. A Offensiva, Rio de Janeiro, ano II, n. 61, p. 6, 13 jul. 1935a. . Educação physica II. A Offensiva, Rio de Janeiro, ano II, n. 53, p. 4, 18 maio 1935b. . Educação physica III: definição e importância. A Offensiva, ano II, n. 54, p. 6, 25 maio 1935c. . Educação physica IV: definição e importância. A Offensiva, Rio de Janeiro, ano II, n. 55, p. 6, 1 jun. 1935 d. . Educação physica: finalidades. A Offensiva, Rio de Janeiro, ano II, n. 56, p. 6, 8 jun. 1935e. . Educação physica XVIII: plano geral. A Offensiva, Rio de Janeiro, ano II, n. 69, p. 5, 7 set. 1935 f.

MALVANO, L. O mito da juventude transmitido pela imagem: o fascismo italiano. In: LEVI, G.; SCHIMITT, J. História dos jovens 20: a época contemporânea. São Paulo: Companhia das Letras, 1996. p.259-90.

MELO, V.A. (Org.). Os sports e as cidades brasileiras: transição do século XIX e XX. Rio de Janeiro: Apicuri, 2010. MONITOR INTEGRALISTA. Rio de Janeiro, ano V, p.3, 10 abr. 1937.

PENNA, B. A mulher e a família, o lar e a escola. In: SALGADO, P. (Org.). Enciclopédia do integralismo. Rio de Janeiro: Clássica Brasileira, 1959. v.9, p.41-59.

SALGADO, P. O juramento. A Offensiva, Rio de Janeiro, ano I, n. 32, p. 1, 20 dez. 1934. . Para se compreender este livro. In: SALGADO, P. (Org.). Enciclopédia do Integralismo. Rio de Janeiro: Clássica Brasileira, 1959. v.9, p.7-14.

SILVA, A.L.S. A perfeição expressa na carne: a educação física no projeto eugênico de Renato Kehl (1917 a 1929). Dissertação (Mestrado em Ciências do Movimento Humano) - Escola de Educação Física, Universidade Federal do Rio Grande do Sul, Porto Alegre, 2008.

SOARES, C.L. Prefácio. In: OLIVEIRA, M.A.T. Educação do corpo na escola brasileira. Campinas: Autores Associados, 2006. p.ix-xiv.

ENDEREÇO

Renata Duarte Simões

R. dos Comerciários, 155

29108-490 - Vila Velha - ES - BRASIL e-mail: renasimoes@hotmail.com
Recebido para publicação: 13/ 10/2011

Revisado: 02/ 03/2012

Aceito: 02/05/2012 